\title{
FORMULAÇÃO DE POLÍTICA PÚBLICA DE SAÚDE: ANÁLISE DO PROJETO TEIAS À LUZ DO MODELO DOS MÚLTIPLOS FLUXOS DE KINGDON ${ }^{1}$
}

\author{
Maria Gracinda Carvalho Teixeira ${ }^{2}$ \\ Antonio Lima Ornelas ${ }^{3}$
}

http://dx.doi.org/10.1590/1413-2311.201.66388

\section{RESUMO}

O objetivo deste artigo é caracterizar as circunstâncias que favoreceram a entrada do Projeto Teias nas agendas públicas do município do Rio de Janeiro, do estado e da União, formulado pela Fundação Oswaldo Cruz e destinada à população do Complexo de Manguinhos. Escolheu-se o Modelo dos Múltiplos Fluxos de John Kingdon como fio condutor teórico e metodológico capaz de permitir a compreensão dos fatores mais relevantes que influenciaram a elaboração da política analisada. Pautados nesse modelo e nos relatos dos sujeitos que participaram da formulação da política em questão, os resultados da pesquisa autorizam salientar como o fluxo político marca presença importante no processo de formulação, bem como comprovar o viés pouco convencional de garbage can ou "lata de lixo", impresso no Modelo dos Múltiplos Fluxos.

Palavras-chave: Política Pública. Modelo dos Múltiplos Fluxos. Janela Política. Saúde Pública. Saúde da Família.

\section{FORMULATION OF PUBLIC HEALTH POLICY FOR THE POPULATION OF MANGUINHOS COMPLEX: ANALYSIS IN THE LIGHT OF KINGDON'S MULTIPLE STREAMS MODEL}

\footnotetext{
${ }^{1}$ Recebido em 23/07/2016, aprovado em 23/10/2017.

${ }^{2}$ Universidade Federal Rural do Rio de Janeiro - Seropédica/RJ (Brasil)- gracinda@uol.com.br

${ }^{3}$ Fundação Oswaldo Cruz (Brasil) - antonio.ornelas1972@gmail.com
} 


\begin{abstract}
The goal of this paper is to characterise the circumstances favouring the insertion of the Teias Projec in the public agenda of the city and state of Rio de Janeiro, as well as the Brazilian Federal Government, formulated by Oswaldo Cruz Foundation, and intended to the population of the Manguinhos Complex. We chose John Kingdon's Multiple Stream Model as the theoretical and methodological line to follow, to allow the understanding of the most relevant factors that influenced the production of the policy analysed here. Based in this model and in the accounts of the subjects who participated in the public policy formulation, the results of our research allowed pointing out how the political flow mark important presence in the process of formulation, as well as demonstrate the unconventional bias garbage can be expressed on the Multiple Streams Model.
\end{abstract}

Keywords: Public Policy. Multiple Streams Model. Policy Window. Public Health. Family's Health.

\title{
FORMULACIÓN DE POLÍTICA DE SALUD PÚBLICA PARA LA POBLACIÓN DEL COMPLEJO DE MANGUINHOS: ANÁLISIS TENIENDO EN CUENTA LO MODELO DE MÚLTIPLES FLUJOS DE KINGDON
}

\section{RESUMEN}

El propósito de este artículo es caracterizar las circunstancias que favorecieron la entrada del proyecto Teias en las agendas públicas de Rio de Janeiro, el estado y la Unión, formulada por la Fundación Oswaldo Cruz para la población del Complejo de Manguinhos. Eligió el Modelo de múltiples flujos de John Kingdon como conductor teórico y metodológico capace de permitir la comprensión de los factores más relevantes que han influido en el desarrollo de la política analizada. Basado en este modelo y en las cuentas de los sujetos que participaron en la formulación de la política en cuestión los resultados de la investigación permitió señalar cómo el flujo político presentar importante en el proceso de formulación, así como demostrar la no convencional garbage can o bote de basura expresa en el Modelo de Múltiples Flujos.

Palabras-clave: Política Pública. Modelo de Múltiples Flujos. Ventana Política. Salud pública. Salud de la familia.

REAd | Porto Alegre - Vol. 24 - No 1 - Janeiro / Abril 2018 - p. 179-207 


\section{INTRODUÇÃO}

A partir da segunda metade do século XX surge um novo campo de conhecimento, voltado para as relações entre Estado, governo, governantes e cidadãos. Esse novo campo ficou conhecido por policy studies, policy analysis ou ainda policy process (HEIDEMANN, 2009; FREY, 2000; RADAELLI, 1995). Ainda que, quando traduzidos para o português, os termos, 'estudos', 'análise', 'processo' e 'política' possam assumir significados bem amplos, na língua inglesas essas são expressões propriamente empregadas para designar a Análise de Políticas Públicas, sendo, na sua origem, uma acepção restrita de uma subárea da disciplina Ciência Política. Mais recentemente outros campos disciplinares passaram a se interessar pela análise de políticas públicas, entre eles, o de Administração, nos estudo das organizações.

Uma política pública pode ser compreendida a partir de uma série de atividades políticas. É seguindo essa linha de raciocínio que se elabora a ideia de policy cicle ou ciclo de políticas públicas. Hoppe, Van de Graaf e Van Dijk (1987) preconizam seis fases para uma política pública: construção da agenda, elaboração do projeto, adoção do projeto, implementação, avaliação e reajuste. Contudo, a literatura destaca mais comumente o trabalho de Howlett, Ramesh e Perl (2013), que dividem esse ciclo em cinco estágios: entrada na agenda, formulação da política, tomada de decisão, implementação da política e avaliação da política. As ações que antecedem a implementação, em conjunto, são denominadas pelos autores de agenda setting. Diversos modelos de análise foram desenvolvidos com a finalidade de melhor compreender esses processos de formação da agenda pública, entre eles, o Multiple Streams Model ou Modelo dos Múltiplos Fluxos, de John Kingdon. Sua construção teórica pressupõe que o surgimento de uma política pública se dá a partir da confluência favorável de três fluxos: problemas, soluções e política (KINGDON, 2011).

Quando se fala em formulação de políticas públicas no Brasil, especificamente no caso da saúde, é fundamental mencionar a Fundação Oswaldo Cruz (Fiocruz), que se constitui dentro do ordenamento jurídico brasileiro como uma fundação pública de natureza autárquica, cujo objetivo é promover a saúde e a cidadania através de atividades que incluem ensino, pesquisa e produção, com foco no desenvolvimento tecnológico em inovações que atendam as principais necessidades de saúde da população (FIOCRUZ, 2008).

Em contraste, é também nessa região que se localiza um dos maiores conjuntos de comunidades carentes do município do Rio de Janeiro: o Complexo de Manguinhos, um espaço social heterogêneo, territorialmente vulnerável, caracterizado pela incerteza no 
provimento de serviços públicos essenciais, pela provisoriedade das moradias e pelos conflitos vinculados ao comércio ilegal de drogas (FERNANDES; COSTA, 2009).

O Projeto Teias (Território Integrado de Atenção à Saúde) - Escola Manguinhos une a Fundação Oswaldo Cruz, o Governo do Estado e a Secretaria Municipal de Saúde, a fim de promover o acesso regular da população moradora do Complexo de Manguinhos às ações e aos serviços de saúde.

Tendo em vista esses fatores, o objetivo do artigo é caracterizar, com base no Multiple Streams Model, as circunstâncias que favoreceram a entrada do Projeto Teias Escola Manguinhos nas agendas públicas do município do Rio de Janeiro, do estado e da União.

\section{MODELOS ANALíticos DE POLÍticas PÚblicas E ASPECTOS CONCEITUAIS}

De acordo com Souza (2007), coube a Lasswell, ainda nos anos 1930, a primeira utilização da expressão policy analysis como campo de conhecimento, sendo o conceito de policy makers ou formuladores de políticas, introduzido por Simon em 1957. A definição de política pública que se tornou mais conhecida foi justamente a de Lasswell que, ao tentar conciliar a produção acadêmica com o conhecimento empírico gerado pelos governos, procurava respostas para as seguintes perguntas: quem ganha o quê, por que e que diferença faz.

Entretanto, existem divergências sobre o conceito de política pública. Thomas Dye (2009), por exemplo, define política pública a partir de um ponto fundamental: o agente primário criador da política pública será sempre um governo, pois somente as instituições governamentais dão às políticas públicas 'legitimidade' e 'universalidade', além de monopolizarem 'a coerção na sociedade' (DYE, 2005, p. 101).

Howlett, Ramesh e Perl (2013, p. 5) apresentam a seguinte definição de política pública: "trata fundamentalmente de atores cercados por restrições que tentam compatibilizar objetivos políticos com meios políticos, num processo que pode ser caracterizado como resolução aplicada de problemas". Essa noção de política pública que a restringe a sua condução pelo Estado é encontrada também no Dicionário de Política, organizado por Bobbio, Matteuci e Pasquino, em 1995.

Há, porém, adeptos da abordagem multicêntrica, como Heidemann (2009) e Secchi (2010), entre outros, para os quais o aspecto fundamental de uma política pública é a 
intenção de resolver um problema público, pouco importando a natureza jurídica do ator que se propõe a solucioná-lo. De acordo com essa visão, a formulação e implementação de políticas públicas não são exclusividade do Estado e podem surgir de organismos privados, organismos não governamentais além de outros atores não estatais.

Para fins deste artigo julga-se mais apropriada a perspectiva de que se reconhece a relevância de atores não estatais no processo de elaboração de políticas públicas, sem abrir mão, contudo, do protagonismo do Estado como condutor desse processo. Entre inúmeros fatores que sustentam este posicionamento podemos citar o fato de que a formulação de políticas públicas é uma das razões mais importantes para a própria existência do Estado, além de outras prerrogativas legítimas, como a de controlar a maior parte dos recursos nacionais. Em outras palavras, significa dizer que o 'fazer' políticas públicas é o Estado em ação (VIANA, 1996). Esse ponto de vista é compartilhado por Bobbio, Matteuci e Pasquino (1995), para quem a política pública é determinada pela união de diretrizes, medidas e processos que exprimem a orientação política do Estado e regulam as atividades governamentais pautadas pelas tarefas de interesse público, influenciando as realidades econômica, social e ambiental.

Destacam-se na literatura três modelos analíticos principais que buscam explicar a formulação e a alteração das agendas de políticas públicas: o modelo de Múltiplos Fluxos (Multiple Streams Model), elaborado em 1995 por John Kingdon; o Modelo do Equilíbrio Interrompido (Punctuated Equilibrium Model), formulado por Frank Baumgartner e Brian Jones em 1993; e o modelo Coalizão de Defesa (Advocacy Coalition), desenvolvido originalmente por Paul Sabatier e Hank Jenkins-Smith em 1993 e rediscutido em um novo trabalho dos autores em 1999.

O modelo Advocacy Coalition concede grande relevância a fatores como crenças, valores e ideias, na formulação de políticas públicas, formando dimensões que possibilitam “alterações relativamente duradouras de mentalidade e de comportamentos intencionais das quais resultam novas experiências e/ou informações capazes de rever os objetivos das políticas” (SABATIER; JENKINS-SMITH, 1999, p. 123).

O Punctuated Equlibrium Model pode ser caracterizado pela tentativa de analisar, tanto os períodos estáveis, como os de rápida mudança no âmbito do processo de uma determinada Política Pública. O que esse modelo pretende é opor-se a ideia de incrementalismo, na medida em que explica como certas ideias, de maneira imprevisível, disseminam-se repentinamente, ocupando o lugar antes tomado por soluções obsoletas e 
concedendo espaço para o surgimento de novas formulações políticas (BAUMGARTNER; JONES, 2010).

Contudo, concede-se, protagonismo, neste trabalho, ao Multiple Streams Model, de John Kingdon. Nele, as agendas das políticas são formadas e modificadas como "resultado da convergência de três fluxos: problemas (problems), soluções ou alternativas (policies) e política (politcs)" (CAPELLA, 2007, p. 89).

No primeiro fluxo, problems streams, o modelo analisa porque questões são compreendidas como problemas e por que esses mesmos problemas passam a fazer parte da agenda governamental. Segundo o autor, existe uma diferença entre problemas e questões: estas só se tornam aqueles quando os formuladores de políticas decidem fazer algo a respeito. Essa decisão, para Kingdon (2011), pode ser orientada por três fatores: existência de indicadores; eventos, crises e símbolos; e feedback sobre programas governamentais em desenvolvimento.

Os indicators constituem uma parte quantitativa do modelo analítico no qual o formulador procura identificar evidências possíveis para orientar sua interpretação a respeito de um determinado problema: tais indicadores são muitos no mundo da política, pois tanto agências governamentais como não governamentais monitoram rotineiramente várias atividades. Os focusing events, crises, and symbols ressaltam a influência dos eventos de grande magnitude que acentuam a atenção em torno de uma determinada questão, reforçando sua caracterização como problema: “Às vezes, essa pressão é provocada por um evento entendido como uma crise ou catástrofe que chama a atenção para o problema, um símbolo poderoso que surge, ou a experiência pessoal de um formulador de políticas" (KINGDON, 2011, p. 94-95). O feedback consiste no retorno de informações sobre outras políticas que podem trazer novos problemas para o centro das atenções dos policy makers como pode ser observado nas palavras do autor:

Esse feedback muitas vezes atrai a atenção para certos problemas: os programas que não estão funcionando como planejado, a execução que não se enquadra com o que manda a legislação, os novos problemas que surgem com a implantação de um programa, ou consequências imprevistas que devem ser corrigidas (KINGDON, 2011, p. 100-101). 
No segundo fluxo, o policy stream, elencam-se as possíveis soluções e alternativas (policy alternatives) para os problemas. Kingdon observa que as ideias que surgem nesse fluxo não se associam, necessariamente, aos problemas identificados no processo de agenda setting: "pessoas não necessariamente resolvem problemas. [...] Em vez disso, elas geralmente criam soluções e, então, procuram problemas para os quais possam apresentar soluções" (KINGDON, 2011, p. 32). Em outras palavras, não há vínculo entre a escolha de problemas e a criação de soluções.

Por fim, o terceiro fluxo é definido por Kingdon como política propriamente dita ou political stream. Ao contrário do policy stream, onde o consenso é formado por meio da persuasão e da propagação das ideias, no fluxo político (political stream) as coalizões desenvolvem-se através da negociação política. O fluxo político é influenciado por três elementos: o clima favorável que concede relevância a certas questões durante um determinado tempo, a organização das forças políticas exercidas por grupos de pressão que podem levar ao consenso ou conflito na arena política e as mudanças em posições estratégicas dentro da estrutura governamental.

Fluindo independentemente ao longo dos fluxos de problemas e soluções está o fluxo político, composto de elementos como o estado de espírito público, campanhas de grupos de pressão, resultados das eleições, distribuições partidárias ou ideológicas no Congresso e mudanças de administração. Independentemente do que acontece na comunidade de especialistas, e muito além de trazer problemas para a atenção das pessoas e em torno do governo, ocorrem eventos como uma nova maioria no Congresso ou uma nova administração. Este desenvolvimento do fluxo político tem um efeito poderoso sobre as agendas, na forma como seus novos itens se tornam proeminentes e como outros são arquivados até um momento mais apropriado (KINGDON, 2011).

A convergência desses três fluxos dá origem a um importante conceito, o de policy window:

A policy window é uma oportunidade para os defensores de propostas empurrarem suas soluções previamente elaboradas, ou para atrair a atenção para os seus problemas específicos. [...] esses defensores gravitam em torno do governo com suas soluções à mão, à espera de problemas para encaixá-las, aguardando um desenrolar do fluxo político que possam usar a seu favor. Às vezes, a janela se abre de forma bastante previsível. [...] Em outras vezes, isso acontece de 
forma imprevisível. Empreendedores de políticas devem estar preparados, com a sua proposta pronta, seu problema específico bem fundamentado, para aproveitar quando a oportunidade passar por eles (KINGDON, 2011, p. 165 - tradução nossa).

Em outras palavras, a policy window pode ser definida como um dado momento específico, onde todos os fluxos, aqui já mencionados, conspiram para a criação de um cenário político extremamente favorável para o encontro de um problema com uma determinada solução. Essas janelas políticas são raras e costumam permanecer abertas por pouco tempo. A convergência desses fluxos consiste em um conjunto de circunstâncias favoráveis muito específicas que, por isso mesmo, não são comuns nem usuais. A policy window ou janela política precisa ser aproveitada habilmente pelos formuladores de políticas municiados de soluções que nela se encaixam.

\section{SITUANDO O PROJETO TEIAS COMO POLÍTICA PÚBLICA}

A saúde pode se entendida como um conceito filosófico, científico e prático. Nesse sentido, interessa, a este artigo, compreendê-la como campo de práticas, especialmente a forma como se desenvolvem suas políticas públicas levando-se em consideração a imprevisibilidade e a subjetividade presentes nas dificuldades para montagem das bases estruturais de modelos de organização de serviços de saúde. O conceito de saúde como práxis pode ser resumido como:

Conjunto de atos sociais de cuidado e atenção a necessidades e carências de saúde e qualidade de vida, conformadas em campos e subcampos de saberes e práticas institucionalmente regulados, operado em setores de governo e de mercados, em redes sociais e institucionais (ALMEIDA FILHO, 2011, p. 27).

Entre os principais atores que compõem o cenário social e político em que se inserem as políticas públicas de saúde está o sistema de saúde. Um sistema de saúde pode ser definido como: 
O conjunto de agências e agentes cuja atuação tem como objetivo principal garantir a saúde das pessoas e das populações. [...] As agências são organizações públicas ou privadas, governamentais ou não, que têm como finalidade promover, proteger, recuperar $\mathrm{e}$ reabilitar a saúde dos indivíduos e das comunidades. Assim, fazem parte do sistema de saúde tanto um hospital particular que atende pessoas com planos de saúde como um posto de saúde pertencente a uma prefeitura. Os agentes são profissionais e demais trabalhadores da saúde que, individualmente ou em equipe, realizam ações de saúde, cuidando das pessoas e das comunidades. Não se incluem aí as indústrias farmacêuticas e de equipamentos médico-hospitalares (PAIM, 2012, p. 13).

O marco da Reforma Sanitária no Brasil foi a 8. ${ }^{a}$ Conferência Nacional de Saúde, realizada em 1986. O efeito do intenso debate a que se seguiram os dois anos seguintes, como estudado pelos citados autores, resultou na inclusão da seguridade social na nova Constituição Federal, promulgada em 1988. A lei 8.080, conhecida como "Lei Orgânica da Saúde", iniciou o processo de regulamentação do funcionamento de um modelo público de ações e serviços de saúde, ordenado pelo que viria a ser conhecido como Sistema Único de Saúde (SUS):

Orientado por um conjunto de princípios e diretrizes válidos para todo o território nacional, [o SUS] parte de uma concepção ampla do direito à saúde e do papel do Estado na garantia desse direito, incorporando, em sua estrutura institucional e decisória, espaços e instrumentos para democratização e compartilhamento da gestão do sistema de saúde. [...] Os principais princípios e diretrizes do SUS estabelecidos na Lei Orgânica da Saúde são: universalidade de acesso em todos os níveis de assistência [...], igualdade na assistência à saúde, sem preconceitos ou privilégios de qualquer espécie [...], integralidade da assistência [...], participação da comunidade [...] e descentralização político-administrativa (NORONHA et al., 2011, p. 435). 
A regulamentação estrita do SUS deu-se através da formulação das Normas Operacionais Básicas (NOBs). A NOB n. ${ }^{\circ}$ 96, em particular, estabeleceu a transferência direta de recursos do Fundo Nacional de Saúde (FNS) para os fundos municipais (Gerschman, 2008). As NOBs instituíram também o Conselho Nacional de Saúde (CNS), o Conselho Nacional de Secretários de Saúde (CONASS) e o Conselho Nacional de Secretários Municipais de Saúde (CONASEMS) como instâncias deliberativas de participação e incorporação da sociedade. Em 2002, a criação da Comissão Intergestorial (CITI) consolida a articulação entre os ministérios da Educação, Trabalho e Meio Ambiente e, três anos depois, a avaliação das condições de concessão do programa Bolsa Família passa a ser responsabilidade do SUS (GERSCHMAN, 2008).

É relevante ressaltar o trabalho de Rivera e Artmann que realizaram um inventário do que consideram as quatro correntes principais no que diz respeito ao planejamento e a gestão em saúde no Brasil. De acordo com os autores, essas vertentes são marcadas não só "pelos desafios prático-teóricos e diversidade de influências teóricometodológicas" (RIVERA; ARTMANN, 2010, p. 2267) como também pela militância sociopolítica vinculada à já citada Reforma Sanitária.

A primeira vertente associa-se ao grupo liderado pelo Laboratório de Planejamento (LAPA) da Faculdade de Medicina de Campinas. As premissas de seu modelo, compreendido como de gestão colegiada e democrática, apresenta como premissas: "forte autonomia, colegiados de gestão, comunicação lateral e ênfase na avaliação para aumentar a responsabilidade" (RIVERA; ARTMANN, 2010, p. 2267). De uma forma geral, essa corrente posiciona-se contra a hierarquização dos serviços, aproximando-se de um modelo que enfatiza a coordenação horizontal em todos os níveis e a centralidade da rede básica de atendimento.

A segunda, intitulada de "planejamento estratégico comunicativo", é representada por núcleos da Escola Nacional de Saúde Pública Sérgio Arouca (ENSP/Fiocruz) e baseia-se essencialmente em um referencial teórico habermasiano, fundamentado na teoria do agir comunicativo. Nesse sentido, incorpora ao planejamento, componentes como "gestão pela escuta, [...] práticas de argumentação, negociação, dimensão cultural, redes de conversação" e posiciona-se como crítica ao paradigma estratégico, recebendo, também, contribuições de um referencial psicossociológico "à gestão organizacional e ao desenvolvimento das capacidades de liderança" (RIVERA; ARTMANN, 2010, p. 2267).

A terceira, denomina-se corrente da "vigilância à saúde". Caracteriza-se pela heterogeneidade geográfica e institucional postulando "um modelo de vigilância à saúde que 
propõe pensar numa inversão do modelo assistencial" (RIVERA; ARTMANN, 2010, p. 2267). Significa dizer que seu posicionamento se opõe ao conceito de verticalização dos programas de saúde, trazendo a necessidade de integração transversal de seus componentes cuja base de seus alicerces assistenciais está o modelo de médico de família.

A Faculdade de Medicina da Universidade de São Paulo (USP) lidera a escola da ação programática. Sua ênfase recai sobre formas multidisciplinares de trabalho em equipe privilegiando maior integração e coordenação do atendimento, sustentando a necessidade "de uma abertura programática por grupos humanos amplos, para além de um recorte por patologias" (RIVERA; ARTMANN, 2010, p. 2267).

Realizada em 2005, a 12. ${ }^{\text {a }}$ Conferência Nacional de Saúde definiu o Programa Saúde da Família (PSF) como ator central da política de saúde brasileira voltado para a atenção básica à saúde com foco na unidade familiar e construído operacionalmente na esfera comunitária o PSF surgiu formalmente no Brasil como política pública de saúde no ano de 1994. Dez anos depois, contava com mais de 20 mil equipes cobrindo cerca de $90 \%$ dos municípios brasileiros, o que equivale a mais de 70 milhões de pessoas (ANDRADE; BEZERRA; BARRETO, 2005).

É justamente o PSF que, em Manguinhos, constitui a porta de entrada principal e ordenadora do acesso aos demais serviços. Considerado a principal ação do Projeto Teias, o PSF está estruturado em treze equipes compostas cada uma por um médico, um enfermeiro, um técnico de enfermagem e seis agentes comunitários de saúde. Cada equipe é responsável por cobrir uma subdivisão do território de Manguinhos ocupando-se de aproximadamente 3.000 (três mil) moradores. Conforme registra o documento "A experiência do Território Escola Manguinhos na Atenção Primária de Saúde" (2012), são ao todo aproximadamente 200 (duzentos) profissionais envolvidos e duas unidades ambulatoriais: a Clínica da Família Victor Valla e o Centro de Saúde Escola Manguinhos (CSE). Existe uma única porta de entrada para urgências e emergências que é a Unidade de Pronto Atendimento (UPA).

O Núcleo de Apoio à Saúde da Família (NASF) constitui uma retaguarda especializada de assistência voltada para o suporte técnico-pedagógico às equipes de saúde da família. Dentro do NASF, surgiu o embrião do Programa de Atenção Domiciliar (PAD), que consiste no cuidado diferenciado e por breve período aos idosos com dependência, pacientes acamados, deficientes, jovens vítimas da violência (paraplégicos vítimas de causas externas), entre outros casos, como se verifica no documento mencionado no parágrafo anterior.

Outra iniciativa deste programa é a atenção à saúde da população de rua, conhecida pelo nome Consultório na Rua. Em Manguinhos, os moradores de rua encontram- 
se, em sua grande maioria, envolvidos com o uso abusivo de drogas, principalmente o crack, e o álcool. O Consultório na Rua visa garantir para essa população o acesso à atenção à saúde de forma rápida e eficiente, através da estratégia de redução de danos, estabelecida pelo Ministério da Saúde como mais adequada a este contexto.

A Academia Carioca da Saúde também compõe o portfólio de atuação do Projeto Teias. Sua proposta é promover a atividade física no território como forma de prevenção e controle das doenças cardiovasculares e outras condições crônicas. Também tem o objetivo de disseminar a adoção de um estilo de vida mais saudável.

No caso específico de Manguinhos, o principal programa de benefícios do governo federal, o Bolsa Família, também está integrado ao Projeto Teias. Identifica-se, ainda no documento "A experiência do Território Escola Manguinhos na Atenção Primária de Saúde" (2012), que este programa é dirigido às famílias cujos membros têm uma renda média de até $\mathrm{R} \$ 140,00$. Os valores pagos à família consideram a renda, o número de crianças e jovens até 17 (dezessete) anos e o número de gestantes e mulheres amamentando. Para participar do programa, a família deve cumprir algumas condições, como garantir a frequência escolar das crianças e jovens, manter a vacinação em dia, ir às consultas na unidade de saúde, entre outras, conforme visto no mencionado documento.

A administração do Projeto Teias - Escola Manguinhos estabelece-se através de uma parceria regulada por um contrato de gestão celebrado entre a ENSP e a Secretaria Municipal de Saúde (SMS), por meio da Fundação para o Desenvolvimento Científico e Tecnológico em Saúde (Fiotec). A Fiotec é a fundação de apoio vinculada à Fiocruz, convertida juridicamente em Organização Social para fins de adequação ao modelo de gestão municipal dos serviços de saúde. Neste modelo, diversos profissionais são contratados pelo regime celetista através das Organizações Sociais (OSs), o que acontece também no Projeto Teias.

Na tentativa de dar validade à participação cidadã no âmbito do projeto, a gestão do Teias Escola - Manguinhos trabalha em conjunto com o Conselho Gestor Intersetorial (CGI), com os Conselhos Internos das Clínicas da Família além de possuir o auxílio de apoiadores institucionais. O CGI de Manguinhos é composto por 48 (quarenta e oito) conselheiros, de forma paritária na participação do poder público e da comunidade, incluindo além da representação do setor Saúde, o setor da Educação e da Assistência Social. O CGI tem a função de acompanhar, pactuar e fisscalizar as ações de saúde na Atenção Primária, realizadas em Manguinhos. 
A ação dos apoiadores institucionais tem como objetivo a modificação das práticas convencionais de coordenação, planejamento, supervisão e avaliação através da construção de espaços de análise antes negligenciados, vinculados essencialmente aos problemas concretos e circunstanciais inerentes a relação das políticas de saúde com as demais políticas. Em outras palavras, pode-se dizer que os apoiadores institucionais atuam como agentes facilitadores ao tentar preencher lacunas de diálogo entre gestores, trabalhadores e usuários.

\section{METODOLOGIA}

A pesquisa é de caráter analítico, visto que se pretendeu analisar como se deu a formulação de uma política pública onde estão articuladas entre si uma organização pública, diferentes esferas de governo e um complexo de comunidades.

Tem sido crescente o interesse por pesquisas qualitativas no âmbito dos estudos das organizações, tendo aumentado significativamente os que se debruçam sobre políticas públicas de planejamento urbano, educação, saúde entre outras, contribuindo para fornecer "descrições ricas e bem fundamentadas, além de explicações sobre processos em contextos locais identificáveis" (VIEIRA, 2004, p. 18), configurando-se também seu caráter descritivo. Assim definiu-se a presente pesquisa como de corte "seccional com perspectiva longitudinal" onde a "coleta de dados é feita em um determinado momento, mas resgata dados e informações de outros períodos passados" (VIEIRA, 2004, p. 21).

São doze as principais comunidades do Complexo de Manguinhos, listadas a seguir por ordem de ocupação: Parque Oswaldo Cruz / Morro do Amorim / Amorim, Parque Carlos Chagas / Varginha, Parque João Goulart, Vila Turismo (a "zona sul” do complexo), Centro de Habitação Provisória 2 (CHP2), Vila União, Conjunto Nelson Mandela, Conjunto Samora Machel (nome dado em homenagem à esposa de Nelson Mandela), Comunidade Mandela de Pedra, Conjunto Samora II / Embratel, Comunidade Vitória de Manguinhos / Conab e Comunidade Embratel / Nova Mandela (FERNANDES; COSTA, 2009). De acordo com o censo domiciliar, realizado em 2010, moram no local aproximadamente quarenta mil pessoas.

A estratégia de aperfeiçoamento do SUS, proposta pelo Ministério da Saúde, assenta-se sobre um modelo que entenda as particularidades dos sistemas locais integrandoos à rede regionalizada e hierarquizada de acordo com a complexidade dos serviços. A 
atenção primária à saúde constitui a porta de entrada principal e ordenadora do acesso aos demais serviços.

Em Manguinhos, essa porta de entrada é constituída pelo Programa Saúde da Família (PSF), a principal ação do Projeto Teias, estruturada em treze equipes compostas cada uma por um médico, um enfermeiro, um técnico de enfermagem e 6 (seis) agentes comunitários de saúde (TEIAS, 2012). Cada equipe é responsável por cobrir uma subdivisão do território de Manguinhos ocupando-se de aproximadamente três mil moradores. Conforme registra o documento "A experiência do Território Escola Manguinhos na Atenção Primária de Saúde" (2012), são ao todo aproximadamente duzentos profissionais envolvidos e duas unidades ambulatoriais: a Clínica da Família Victor Valla e o Centro de Saúde Escola Manguinhos (CSE). Existe uma única porta de entrada para urgências e emergências que é a Unidade de Pronto Atendimento (UPA).

Os dados da pesquisa empírica foram coletados por meio de fontes orais através de entrevistas em profundidade nos moldes de Easterby-Smith, Thorpe e Lowe (1991). Os sujeitos de pesquisa foram selecionados segundo o cumprimento de ao menos um dos seguintes requisitos, enquanto atores envolvidos com a elaboração do Projeto Teias - Escola Manguinhos: (a) o sujeito ter participado da formulação técnica do Projeto Teias - Escola Manguinhos; (b) o sujeito ter participado da articulação política que resultou na formulação do Projeto Teias - Escola Manguinhos; (c) o sujeito ter ocupado cargo de nível decisório relevante com referência às ações adotadas para elaboração do Projeto Teias - Escola Manguinhos; e (d) o sujeito ser comprovadamente detentor de notório saber na área da saúde pública e coletiva. Excluem-se desses critérios características pessoais como gênero e idade.

\section{Quadro 1 - Sujeitos da Pesquisa}

\begin{tabular}{|l|l|}
\hline \multicolumn{1}{|c|}{ Sujeitos } & \multicolumn{1}{c|}{ Descrição } \\
\hline Entrevistado 1 & Diretor da Escola Nacional de Saúde Pública Sérgio Arouca \\
\hline Entrevistado 2 & Coordenador do Projeto Teias - Escola Manguinhos \\
\hline Entrevistado 3 & Gerente do Projeto Teias - Escola Manguinhos \\
\hline Entrevistado 4 & Vice-Presidente de Gestão e Desenvolvimento Institucional da Fiocruz \\
\hline Entrevistado 5 & Coordenador de Cooperação Social da Fiocruz \\
\hline Entrevistado 6 & Secretária Executiva do Fórum do Movimento Social de Manguinhos \\
\hline Entrevistado 7 & $\begin{array}{l}\text { Coordenador de Projetos Estratégicos / Analista de Planejamento em } \\
\text { Saúde }\end{array}$ \\
\hline
\end{tabular}

Fonte: elaborado pelos autores.

Os dados foram analisados com o uso da técnica de análise de conteúdo conforme Bardin (1977, p. 42), para quem é "um conjunto de técnicas de análise das comunicações” e também com auxílio na abordagem de Lasswell (1987), no que foi possível caracterizar a 
análise de conteúdo a partir de seis questões: (a) quem fala?; (b) para dizer o quê?; (c) a quem?; (d) de que modo?; (e) com que finalidade?; e (f) com que resultados. Seguindo o procedimento de análise proposto pelo mencionado autor, entende-se que a pergunta a ser respondida aqui é “para dizer o quê?”. Precisamente, escreve Lasswell (1987, p. 105, grifo do autor): “os especialistas que focalizam o 'diz o quê' ocupam-se da análise do conteúdo".

\section{Quadro 2 - Categorias de Análise - Modelo de Múltiplos Fluxos - Agenda Setting}

\begin{tabular}{|c|c|c|c|}
\hline Categoria & Definição Categoria & Unidades de Análise & Operacionalização \\
\hline \multirow[b]{3}{*}{ Problems Stream } & \multirow[b]{3}{*}{$\begin{array}{l}\text { O modelo pretende analisar } \\
\text { porque questões são } \\
\text { compreendidas como } \\
\text { problemas e por que esses } \\
\text { mesmos problemas passam } \\
\text { fazer parte da agenda } \\
\text { governamental (Kingdon, } \\
2011 \text { ). }\end{array}$} & Indicadores & \multirow{3}{*}{$\begin{array}{l}\text { Interpretação dos policy } \\
\text { making para as avaliações } \\
\text { das intervenções anteriores } \\
\text { no território do Complexo } \\
\text { de Manguinhos. Eventos } \\
\text { que sinalizaram a } \\
\text { importância do } \\
\text { realinhamento das ações em } \\
\text { um novo conjunto de } \\
\text { iniciativas. Novas } \\
\text { configurações que podem } \\
\text { significar o surgimento de } \\
\text { novos problemas. } \\
\end{array}$} \\
\hline & & Eventos, crises e símbolos & \\
\hline & & Feedback & \\
\hline Policy Stream & $\begin{array}{l}\text { Elencam-se as possíveis } \\
\text { soluções e alternativas (policy } \\
\text { alternatives) para os } \\
\text { problemas. As ideias que } \\
\text { surgem nesse fluxo não se } \\
\text { associam, necessariamente, } \\
\text { aos problemas identificados } \\
\text { no processo de agenda setting } \\
\text { (Kingdon, 2011). }\end{array}$ & $\begin{array}{l}\text { Vertente sanitarista } \\
\text { predominante }\end{array}$ & $\begin{array}{l}\text { Pensamento teórico que } \\
\text { orienta a formulação de } \\
\text { políticas públicas. Tipo de } \\
\text { abordagem central a ser } \\
\text { adotada e seu potencial de } \\
\text { articulação com outras } \\
\text { políticas. Arcabouço legal e } \\
\text { administrativo que viabilize } \\
\text { as iniciativas. }\end{array}$ \\
\hline \multirow{3}{*}{ Political Stream } & \multirow{3}{*}{$\begin{array}{l}\text { "Diferentemente do fluxo de } \\
\text { alternativas (policy stream), } \\
\text { em que o consenso é } \\
\text { construído com base na } \\
\text { persuasão e difusão das } \\
\text { ideias, no fluxo político } \\
\text { (political stream) as coalizões } \\
\text { são construídas em um } \\
\text { processo de barganha e } \\
\text { negociação política" } \\
\text { (Capella, 2007, p. 92). }\end{array}$} & Clima & \multirow{3}{*}{$\begin{array}{l}\text { Compreensão da } \\
\text { composição e o peso } \\
\text { político das forças que } \\
\text { influenciaram a formulação } \\
\text { da política pública. }\end{array}$} \\
\hline & & $\begin{array}{c}\text { Organização das forças } \\
\text { políticas }\end{array}$ & \\
\hline & & $\begin{array}{l}\text { Mudanças de posição na } \\
\text { estrutura governamental }\end{array}$ & \\
\hline
\end{tabular}

Fonte: elaborado pelos autores com base em Kingdon (2011) e Capella (2007).

No Quadro 2, visualizam-se as categorias de análise definidas com a finalidade de operacionalizar os conceitos associados às proposições analíticas referentes ao Projeto Teias - Escola Manguinhos, enquanto política pública. Tais categorias são aderentes às perspectivas teóricas essencialmente vinculadas ao Modelo de Múltiplos Fluxos, elaborado por John Kingdon. 


\section{RESULTADOS DA PESQUISA}

Nesta parte do artigo, os três fluxos elaborados por Kingdon são descritos, articulando-os aos relatos dos entrevistados com o intuito de identificar a janela política que beneficiou o surgimento do Projeto Teias - Escola Manguinhos e sua formulação na agenda de políticas públicas do município, do estado e da União.

O problema-saúde tem seu fluxo determinado por aspectos como: (i) a necessidade de aderir mais firmemente às ideias de promoção à saúde e de atenção básica em razão da hegemonia em escala mundial da Estratégia Saúde da Família; (ii) a importância de se avançar para a adoção de um maior grau de integração entre as políticas públicas segundo uma lógica local e territorializada, representada pelo significado do termo teias (território integrado de atenção à saúde) elaborado à época pelo Ministério de Saúde e; (iii) pela obrigação de adaptar o modelo de gestão do acesso a serviços de saúde, em Manguinhos, aos fatores administrativos e legais vinculados a nova política de saúde da Secretaria Municipal de Saúde do Rio de Janeiro, que abolia um instrumento frágil de simples financiamento para buscar formas de intervenção mais articuladas e controladas. O Entrevistado 3, por exemplo, destacou a importância do ajustamento legal nesse contexto:

O que motivou, no início, foi uma pura necessidade legal de adequação. O município não poderia, por força legal, ter todo o município com Saúde da Família gerenciada por OS e apenas um território operando por convênio, ainda mais um convênio frágil. Era o único caminho possível para que o Centro Saúde Escola continuasse a ter equipes de Saúde da Família e, portanto, fazer pesquisa dentro da política nacional de atenção primária. Porque não teria sentido ele não ter equipe de Saúde da Família, ele teria que fechar as portas, ele não pode ser contrário a uma política nacional se ele é também um grande dispositivo de formulação de políticas. A Fiotec teve que se habilitar como OS.

O Entrevistado 4, por outro lado, destacou a necessidade de aperfeiçoamento do modelo enfatizando-se a atenção básica:

O centro da política está localizado em um problema sério do Rio de Janeiro que é a dificuldade de acesso, pouquíssimo acesso à atenção básica. Entopem pronto-atendimentos, entopem emergências, 
desregulam completamente a capacidade de operação do sistema de média e alta complexidade. Se eu não tiver atenção básica não adianta eu achar que vou modelar, vou gerenciar, vou regular adequadamente média e alta complexidade porque o maior volume dos problemas de saúde não precisa de ambulatório especializado.

Entre as principais consequências desse fluxo, incluiu-se a necessidade de articular um modelo de gestão que integrasse, principalmente, a Secretaria Municipal de Saúde e a Fiocruz através da adoção de um arcabouço jurídico-administrativo cujo elemento decisivo foi a conversão da Fiotec em Organização Social, que possibilitou manter a gestão local a cargo da Fiocruz sem, contudo, desrespeitar as regras estabelecidas pela administração pública municipal.

Todavia, um importante componente se juntaria aos demais, fortalecendo sobremaneira o fluxo de problemas e ampliando a possibilidade de surgimento de uma janela política que poderia ser favorável à adoção de novas abordagens: as intervenções territoriais em Manguinhos provocadas, a partir de 2007, pelas obras do Programa de Aceleração do Crescimento. A magnitude das obras do PAC, conforme relataram principalmente os entrevistados 2 e 3 , trouxe mudanças relevantes para a configuração territorial de Manguinhos. Quatro setores foram particularmente mais afetados: saneamento, transporte, habitação e saúde. As três primeiras áreas experimentaram as mudanças mais ou menos de forma conjunta, tendo em vista que o primeiro movimento da política habitacional implicou na remoção de famílias com a posterior demolição de moradias. O novo espaço configurado a partir dessa ação abriu caminho para obras de saneamento básico, para a inserção de novas vias rodoviárias e revitalização de outras, além de promover melhorias vinculadas à malha ferroviária. Com referência à saúde, no sentido estrito, a ação mais relevante do PAC foi acrescentar ao território mais uma unidade médico-hospitalar, além do já existente Centro Saúde Escola: a Clínica da Família Victor Valla integrada a uma unidade de emergência, a UPA. De acordo com o Entrevistado 2:

Também uma coisa que ajudou [...] foi que a gente estava junto com o PAC. [...] Chamamos para conversar a Coordenadoria Geral de Habitação, fizemos diversas reuniões para discutir o projeto saúde na escola. Não mais era um projeto de que a saúde estava chegando à escola. Sabendo que a gente precisava avançar nisso, a gente fez essas articulações. Fizemos reuniões com o pessoal da segurança pública. Na verdade a gente tentou reunir educação, assistência 
social, segurança pública e habitação, muito por conta das mudanças que estavam havendo no PAC. Então fizemos vários encontros $e$ conseguimos melhorar muito os fluxos. Por exemplo, colocamos para conversar o diretor da escola com o diretor da unidade de saúde eles não conversavam, estão no mesmo território há 40 anos, mas não conversavam [...] a gente foi melhorando os fluxos de encaminhamento.

O Entrevistado 3 reforçou ainda o papel do PAC como estimulador da integração: Então, em 2009 o estado chama a gente; eles estavam fazendo as obras do PAC, construíram um espaço onde hoje é a [Clínica da Família] Victor Valla e a UPA, quiseram combinar como seria a administração daquela área com a gente. [...] Eu acho o seguinte: o PAC e a própria Fiocruz trouxeram outros atores. O próprio município, a gestão municipal se tornou mais presente. [...] Aí você começa a ver que dentro do território as coisas são todas fragmentadas. Aqui no território eu tinha que falar com dois coordenadores de educação que eram da terceira CRE [Coordenadoria Regional de Educação] e quarta CRE, dois da ação social porque metade do território é uma ação social, outra metade é outra ação social, aí eu tinha que falar com o estado, eu tinha que falar com o responsável pela polícia, tinha que falar com a cultura. $O$ grande exercício da gente foi conseguir juntar esse povo todo em uma agenda que caminhasse mais ou menos junta. [...] O PAC foi uma instância que fomentou uma integração dos atores no território.

O contexto dessas modificações estruturais no território foi entendido pelos formuladores de políticas públicas, envolvidos, como uma oportunidade de pôr em prática soluções inovadoras segundo o próprio conceito de território-escola, existente já antes do surgimento do Projeto Teias. A opção pela intensificação da promoção à saúde e da atenção básica, essencialmente vinculada à Estratégia Saúde da Família, e, principalmente, a ideia de teias com significado implícito de redes e interconexões, enfim, de território integrado, abria as portas do território para uma experiência nova e supostamente mais efetiva.

Analisando o conteúdo dos depoimentos verificou-se a ênfase em dois fatores que se revelam determinantes para solução do problema-saúde no território. Primeiro, há um razoável consenso de que a experiência de território integrado, ainda que não derive de um 
conceito propriamente novo, consiste em um desafio difícil de ser superado, sendo interpretado pelos atores envolvidos como uma ação bastante ousada e inovadora. Segundo, há uma clara alusão dos entrevistados à capacidade acadêmica e à responsabilidade institucional da Fiocruz de liderar o processo de formulação de novas políticas de saúde por meio de modelos que possam se tornar replicáveis, ao menos em parte, em outros territórios. Segundo o Entrevistado 3, haviam várias pistas de que o momento era bastante favorável a junção desses fatores:

[...] o grupo que estava à frente na época decidiu, vamos ousar, vamos empreender, com a Secretaria Municipal de Saúde que também estava em um movimento muito ousado. Houve uma ampliação de cobertura da saúde da família de 3\% para $40 \%$ no município, isso não é trivial. Existia uma janela de oportunidade de inovação porque a secretaria queria mesmo mudar a lógica do modelo de atenção e investir na atenção primária. Então juntou-se a fome com a vontade de comer. A ENSP com a sua missão de provocar inovações no sistema de saúde de um lado e um grupo de pessoas também a fim disso e aí nós fomos escrevendo, pensando nisso. Então, o motivo inicial foi uma necessidade legal, mas muito aliado a uma possibilidade de inovar, de fato, chacoalhar o Centro Saúde Escola que já existe há 40 e poucos anos. Então também seria uma forma de alavancar o Centro Saúde Escola. Então foi uma confluência favorável, vamos dizer assim..

O Entrevistado 4 acrescenta que:

De fato, há algumas confluências, algumas sinergias. Primeiro a ENSP tem uma atuação na atenção primária, na atenção básica, há décadas. É um espaço já consagrado. A ENSP tem formulação, ela tem análise de formulação para políticas de atenção primária, isso também tem décadas. Eu tenho um governo federal, já desde Haddad, Serra [ministros da saúde no governo FHC], onde a estratégia de saúde da familia é uma estratégia de Estado.

Por sua vez, o Entrevistado 7 destaca a importância de se criar um modelo que pudesse ser replicado:

Foi uma tentativa de criar um modelo exemplar da concepção do modelo de teias em um território determinado, ou seja, na vizinhança 
da Fiocruz - Manguinhos - e capitaneado pela própria Fiocruz na sua função ali de propositora de tecnologias assistenciais, de planejamento e organização de redes de saúde. Quer dizer, ela estaria ali, na verdade, a partir do gerenciamento de um território determinado tentando desenvolver tecnologias de gestão para que pudessem ser aplicadas em outros territórios. Ter uma espécie de teias, modelo aqui dentro da Fiocruz que geraria supostamente tecnologias replicáveis para outros teias, em outros lugare, conforme a política da época do Ministério da Saúde.

Já o fluxo político parece consolidar-se a partir de duas vertentes: a política partidária e a política governamental, esta última subdividida em política federal, estadual e municipal. Com referência à política partidária há um aspecto decisivo: o momento sem precedentes históricos recentes no estado do Rio de Janeiro, onde os cargos de presidente da república, governador do estado e prefeito do município são ocupados por integrantes da mesma coalizão política.

As políticas federal, estadual e municipal de saúde também tentam alinhar-se, partindo de diretrizes determinadas pelo Ministério da Saúde que, em última análise, responde transversalmente pela direção nacional do SUS. Narrando de outra maneira, o preenchimento de cargos estratégicos no Ministério da Saúde, segundo critérios políticos, concede protagonismo momentâneo a um determinado posicionamento epistemológico, em detrimento de outras vertentes. Esse aspecto configura-se como decisivo, na medida em que o comando da Secretaria de Atenção a Saúde passa a ser ocupado por um pesquisador, oriundo da Fiocruz, que articula a ideia de território integrado como base da política nacional de saúde. O encadeamento dos eventos segue uma ordem mais ou menos inequívoca: um pesquisador da Fiocruz preconiza um modelo de política de saúde que deverá ser experimentado em um território sob gestão local da própria Fiocruz. O Entrevistado 4 ressalta importantes aspectos da política partidária envolvida nesse processo:

O Ministério da Saúde, no governo Lula, ele com o Rio e com o município, encontra algo que décadas atrás não existia: os três começaram a conversar. Isso explica uma convergência de recursos. O Sérgio Cabral [governador do Estado do Rio de Janeiro de 2007 a 2013], gostando ou não gostando, colocou muito mais dinheiro na saúde do que os outros governadores colocaram. O município idem. $O$ estado foca no pronto atendimento, as UPAs são do estado, o 
município entra na Saúde da Família, financiado por quem? Quem pagou esse dinheiro? O governo federal. Isso é uma sinergia que se estabelece, digamos aí, mais ou menos nos últimos dez anos.

Já o Entrevistado 7, realça a predominância da ideia de teias dentro da Fiocruz e sua consonância com a política ministerial:

O campo da saúde coletiva no Brasil, nas últimas décadas, como qualquer campo científico, é composto por diversas correntes de posicionamento, com visões diferentes. Algumas enfatizam mais exatamente a questão do território, outras enfatizam mais a questão do cuidado longitudinal com o paciente. Acontece de eventualmente predominar uma ou outra corrente ali no comando, ou seja, nos postos estratégicos dos tomadores de decisão do Ministério da Saúde, por exemplo. O próprio caso do Teias na Secretaria de Atenção à Saúde do ministério pode ser entendido nesse contexto. Você tem ali um conjunto de propositores de uma determinada política, que está no ministério e que está ligado a uma dessas correntes de pensamento teórico no campo da saúde coletiva. Do ponto de vista da Fiocruz há ali a lógica de estar caminhando de forma alinhada à política do ministério. A escolha da Fiocruz foi pegar um conceito que estava ali sendo defendido e fazer um projeto de aplicação desse modelo aqui na Fiocruz [...]. Mas é claro que se esse projeto surge aqui na Fiocruz dessa forma é porque também há a adesão desse modelo, dessa corrente de pensamento pelas pessoas que estão propondo isso dentro da Fiocruz.

A opção pelo Modelo dos Múltiplos Fluxos como elemento central do procedimento metodológico aqui adotado procura, em parte, reproduzir as origens históricas de sua elaboração, ao criar, da mesma forma que o autor, uma base de dados empíricos, obtida por meio de entrevistas com servidores públicos envolvidos nos estágios prédecisórios da formulação de políticas. O modelo de Kingdon tornou-se referência na análise de políticas públicas para pesquisadores que priorizam a centralidade dos governos nesse processo. Nesse sentido, os dados empíricos obtidos foram sintetizados a partir das categorias e unidades de análise definidas no Quadro 2 deste trabalho. Essa sistematização é apresentada no Quadro 3. 
O Modelo dos Múltiplos Fluxos é uma construção intelectual não ortodoxa e por isso pouco familiar. A princípio, pode causar estranheza em razão de sua estrutura fluida e não hierarquizada. A ideia inicial de Kingdon recomendava a independência dos três fluxos, que somente se conectariam naquilo que o autor chamou de policy window.

\section{Quadro 3 - Articulação Entre Teoria e Empiria (Parte 1)}

\begin{tabular}{|c|c|c|c|}
\hline Categoria & Definição Categoria & Unidades de Análise & Síntese dos Dados \\
\hline \multirow{3}{*}{$\begin{array}{l}\text { Problems } \\
\text { Stream }\end{array}$} & \multirow{3}{*}{$\begin{array}{l}\text { O modelo pretende analisar } \\
\text { porque questões são } \\
\text { compreendidas como problemas } \\
\text { e por que esses mesmos } \\
\text { problemas passam fazer parte da } \\
\text { agenda governamental } \\
\text { (KINGDON, 2011) }\end{array}$} & Indicadores & $\begin{array}{l}\text { Atenção básica deficiente no } \\
\text { território; } \\
\text { Baixa cobertura percentual da } \\
\text { Estratégia Saúde da Família no } \\
\text { município (3\%); } \\
\text { Modelo de gestão frágil e } \\
\text { vulnerável. }\end{array}$ \\
\hline & & $\begin{array}{l}\text { Eventos, crises e } \\
\text { símbolos }\end{array}$ & $\begin{array}{l}\text { Chegada em Manguinhos das } \\
\text { obras do Programa de } \\
\text { Aceleração do Crescimento } \\
\text { (PAC); } \\
\text { Definição por parte da Prefeitura } \\
\text { do Município do modelo de } \\
\text { gestão da saúde através de } \\
\text { Organizações Sociais. }\end{array}$ \\
\hline & & Feedback & $\begin{array}{l}\text { Ampliação da cobertura da } \\
\text { Estratégia Saúde da Família para } \\
100 \% \text { em Manguinhos e } 40 \% \text { em } \\
\text { todo o município do Rio de } \\
\text { Janeiro; } \\
\text { Conversão da Fiotec em } \\
\text { Organização Social. }\end{array}$ \\
\hline Policy Stream & $\begin{array}{c}\text { Elencam-se as possíveis soluções } \\
\text { e alternativas (policy } \\
\text { alternatives) para os problemas. } \\
\text { As ideias que surgem nesse fluxo } \\
\text { não se associam, } \\
\text { necessariamente, aos problemas } \\
\text { identificados no processo de } \\
\text { agenda setting (KINGDON, } \\
\text { 2011) }\end{array}$ & $\begin{array}{l}\text { Vertente sanitarista } \\
\text { predominante }\end{array}$ & $\begin{array}{l}\text { Modelo de território integrado de } \\
\text { atenção à saúde (TEIAS). }\end{array}$ \\
\hline \multirow[b]{2}{*}{$\begin{array}{l}\text { Political } \\
\text { Stream }\end{array}$} & \multirow{2}{*}{$\begin{array}{l}\text { "Diferentemente do fluxo de } \\
\text { alternativas (policy stream), em } \\
\text { que o consenso é construído com } \\
\text { base na persuasão e difusão das } \\
\text { ideias, no fluxo político (political } \\
\text { stream) as coalizões são } \\
\text { construídas em um processo de } \\
\text { barganha e negociação política" } \\
\text { (CAPELLA, 2007, p. 92) }\end{array}$} & Clima & $\begin{array}{l}\text { Ambiente de entendimento, } \\
\text { tendo em vista que foram eleitos } \\
\text { para presidente da república, } \\
\text { governador do estado e prefeito } \\
\text { do município, políticos } \\
\text { integrantes da mesma coalizão } \\
\text { partidária. }\end{array}$ \\
\hline & & $\begin{array}{l}\text { Organização das } \\
\text { forças políticas }\end{array}$ & $\begin{array}{l}\text { Ministério da Saúde define a } \\
\text { política nacional de atenção } \\
\text { básica centrada na ideia de } \\
\text { território integrado; } \\
\text { Governo do Estado coordena as } \\
\text { obras do PAC e constrói } \\
\text { equipamentos de saúde; } \\
\text { Prefeitura define o modelo de } \\
\text { gestão da saúde através de } \\
\text { Organizações Sociais; } \\
\text { Fiocruz assume a gestão local } \\
\end{array}$ \\
\hline
\end{tabular}




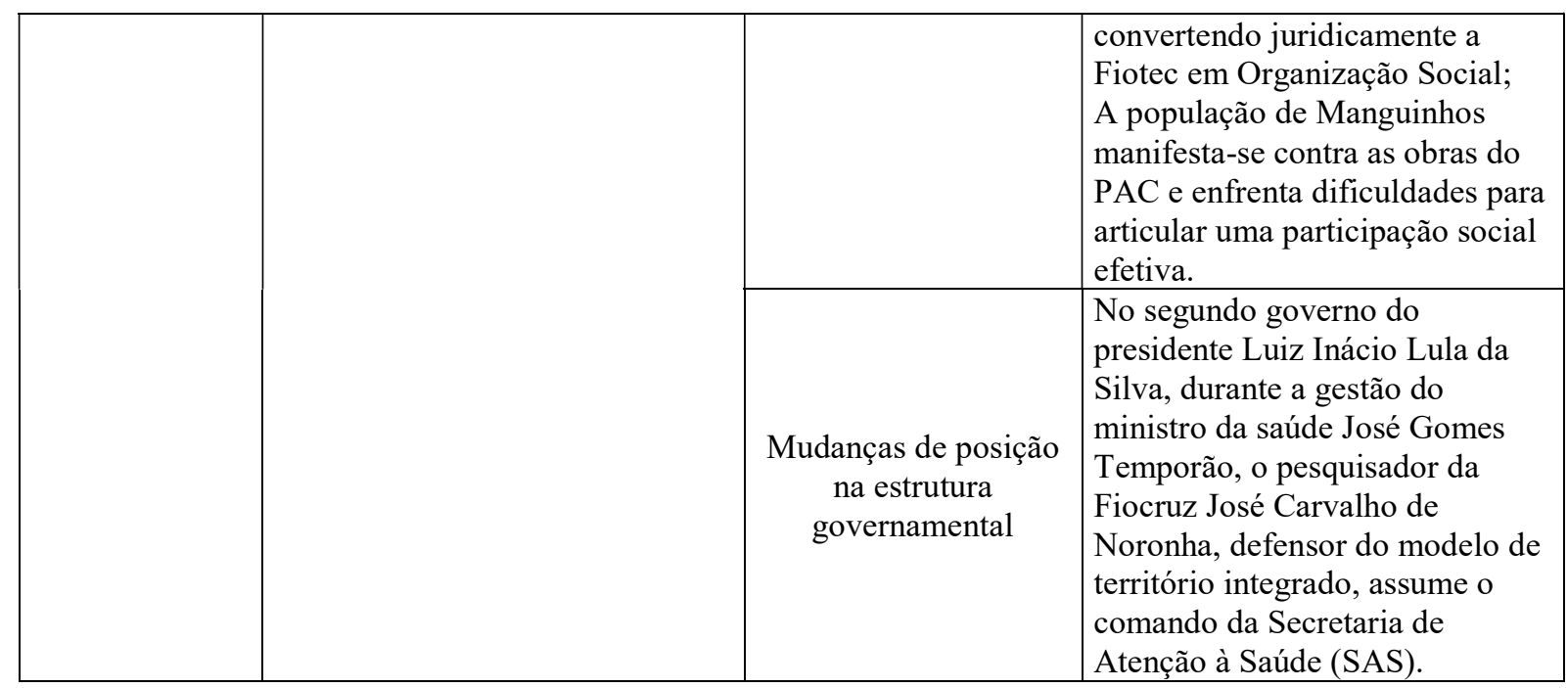

Fonte: elaborado pelos autores.

Contudo, em trabalhos mais recentes, Kingdon (2011) admitiu que, de forma subsidiária, podem ocorrer interdependências entre os três fluxos antes da composição da janela. De fato, isso pode ser verificado dentro do contexto aqui analisado, tendo em vista que fatores vinculados a um dos fluxos relacionam-se, de certa forma, com aspectos associados aos outros dois. Essas relações podem ser mais bem compreendidas através da visualização do Quadro 4.

\section{Quadro 4 - Articulação Entre Teoria e Empiria (Parte 2)}

\begin{tabular}{|c|l|c|l|}
\hline Problems Stream & $\begin{array}{l}\text { Chegada em Manguinhos } \\
\text { das obras do Programa de } \\
\text { Aceleração do } \\
\text { Crescimento (PAC); }\end{array}$ & $\begin{array}{c}\text { Political } \\
\text { Stream }\end{array}$ & $\begin{array}{l}\text { Governo do Estado coordena as obras do } \\
\text { PAC e constrói equipamentos de saúde. }\end{array}$ \\
\hline Problems Stream & $\begin{array}{l}\text { Pefinção por parte da } \\
\text { do modelo de gestão da } \\
\text { saúde através de } \\
\text { Organizações Sociais. }\end{array}$ & $\begin{array}{l}\text { Political } \\
\text { Stream }\end{array}$ & $\begin{array}{l}\text { Prefeitura define o modelo de gestão da } \\
\text { saúde através de Organizações Sociais. }\end{array}$ \\
\hline Policy Stream & $\begin{array}{l}\text { Modelo de território } \\
\text { integrado de atenção à } \\
\text { saúde (TEIAS), com } \\
\text { enfase na abordagem } \\
\text { intersetorial. }\end{array}$ & $\begin{array}{l}\text { Political } \\
\text { Stream }\end{array}$ & $\begin{array}{l}\text { No segundo governo do presidente Luiz } \\
\text { Inácio Lula da Silva, durante a gestão do } \\
\text { ministro da saúde José Gomes Temporão, o } \\
\text { pesquisador da Fiocruz José Carvalho de } \\
\text { Noronha, defensor do modelo de território } \\
\text { integrado, assume o comando da Secretaria } \\
\text { de Atenção à Saúde (SAS). }\end{array}$ \\
\hline
\end{tabular}

Fonte: elaborado pelos autores.

Tais interdependências, de forma alguma invalidam a composição da janela política. Ao contrário, contribuem para salientar, de forma mais objetiva, que elementos são mais vitais para a sua formação. A partir da interpretação do Quadro 4, pode-se verificar que esses elementos, no caso do Projeto Teias - Escola Manguinhos, são: as obras do PAC, que 
constituem-se tanto em problema sob a forma de evento, como em fator decisivo na organização das forças políticas dentro do território; a gestão municipal dos serviços de saúde por Organizações Sociais que, ao mesmo tempo, é "crise" que provoca movimentos de adequação e aspecto central do poder político municipal em Manguinhos e; a adoção do modelo de território integrado de atenção à saúde que configura-se como solução predominante somente após adquirir autoridade política dentro do Ministério da Saúde.

Figura 1 - Composição da Policy Window para o Projeto Teias - Escola Manguinhos

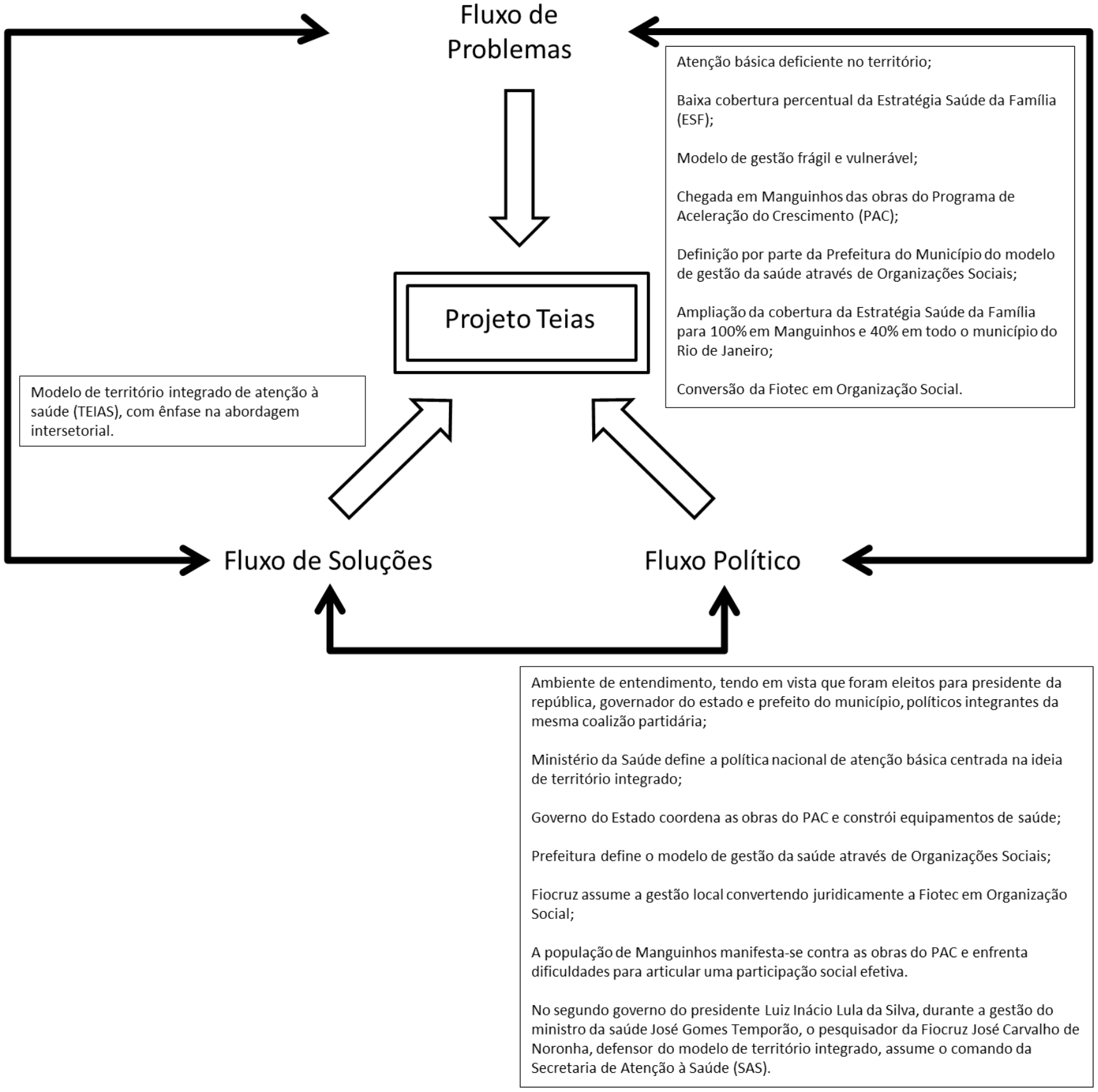

Fonte: elaborado pelos autores. 
Portanto, analisando o conteúdo dos depoimentos coletados, é admissível dizer que a janela política que permitiu a entrada do Projeto Teias-Escola Manguinhos na agenda pública federal, estadual e municipal, caracteriza-se pelos seguintes fatores: (a) a ascensão de uma visão ampliada do processo saúde-doença que havia amadurecido na ENSP, desde a reforma sanitária, mas que até então não possuía uma base sustentável do ponto de vista legal e político para sua aplicação em um dado território; (b) as obras do PAC, um programa do governo federal que tinha como objetivo acelerar o crescimento econômico do país mediante a realização de obras de infraestrutura e o entendimento de que a saúde deveria ser incorporada, localmente, a esse programa; (c) a urgência de se ampliar a cobertura da Estratégia Saúde da Família, saindo de um patamar irrisório para quase metade da população através do modelo de gestão por OSs; (d) a confluência política de interesses das esferas governamentais municipal, estadual e federal que, depois de muitos anos, faziam parte da mesma coalizão partidária; e (e) a ocupação de cargos estratégicos no Ministério da Saúde, como o de Secretário de Atenção à Saúde, por um pesquisador vinculado à Fiocruz, defensor da ideia de território integrado como solução mais viável para os problemas do setor saúde.

Tendo em vista todos esses detalhes, de acordo com a discussão empreendida até aqui, expõe-se a Figura 1, como forma de visualização da policy window que viabilizou a entrada do Projeto Teias - Escola Manguinhos na agenda pública federal, estadual e municipal.

É preciso entender, segundo orienta o Modelo dos Múltiplos Fluxos, que os fatores que compõem o fluxo de problemas representam aspectos detentores de problemas potenciais, ainda nesse estágio, indefinidos. Por exemplo, a conversão da Fiotec em Organização Social, por si só, não é um problema. Mas os impactos da mudança de seu modelo jurídico com a finalidade de adequar-se às diretrizes definidas pela Secretaria Municipal de Saúde poderão ser. A ampliação da Estratégia Saúde da Família para 100\% da comunidade de Manguinhos, embora pareça assumir características de solução, tem implicações implícitas extremamente problemáticas, tais como a maneira como essa ampliação se deu e sua real efetividade. O mesmo pode-se dizer das obras do PAC que, em tese, deveriam ser reconhecidas mais por suas melhorias, mas, não por poucas vezes, associam-se a aspectos negativos, como foi o caso da remoção de moradores.

\section{CONSIDERAÇÕES FINAIS}


O presente artigo caracterizou as circunstâncias que favoreceram a entrada do Projeto Teias - Escola Manguinhos nas agendas públicas do município do Rio de Janeiro, do estado e da União. Escolheu-se o Modelo dos Múltiplos Fluxos de John Kingdon como fio condutor teórico e metodológico por compreendê-lo como capaz de permitir o entendimento dos fatores mais relevantes que influenciaram a formulação da política analisada.

A análise desenvolveu-se segundo a concepção de que as políticas públicas são expressões do Estado em ação, portanto vinculadas essencialmente às intervenções governamentais. Admitir a centralidade dos governos em sua formulação, tendo em vista o modelo federativo brasileiro que demanda a conciliação de três esferas políticas, administrativas e legais, marca um posicionamento epistemológico que reverbera sobre todo o trabalho.

Também foi fundamental traçar um resumido panorama sobre o contexto da saúde pública no Brasil. Nesse sentido foi fundamental atribuir relevância a eventos importantes como a Reforma Sanitária Brasileira, o nascimento do SUS e a ascensão da Estratégia de Saúde da Família.

A articulação da teoria com a empiria, por meio da análise do conteúdo, resultou em um esforço descritivo que abrangeu desde importantes peculiaridades territoriais do Complexo de Manguinhos até as relações mais intrincadas do poder público com as demandas da população no território. Buscou-se, também, jamais perder de vista o protagonismo da Fundação Oswaldo Cruz em todo esse processo.

De forma sintetizada, o Projeto Teias - Escola Manguinhos é aqui descrito como uma política pública de saúde formulada em um contexto de mudanças. Mudanças essas que envolvem as consequências de intervenções de grande relevância como as promovidas pelo PAC, criado pelo governo federal e implementado em Manguinhos pelo governo do estado. Inclui-se, também, a adoção, por parte do governo municipal, responsável pela atenção básica, do modelo de gestão por OSs. Soma-se a isso a ascensão, em nível ministerial, da ideia de território integrado de atenção à saúde (teias) e a vocação da Fiocruz para produzir conhecimento tendo à sua disposição um território-escola. Nesse sentido, comprovou-se a eficácia do modelo de Kingdon, que permitiu elencar os fatores que contribuíram para a abertura da "janela política" que conduziu o Projeto Teias para dentro da agenda pública das três esferas governamentais.

Por fim, entende-se que o presente trabalho apresenta ao menos duas contribuições relevantes para os estudos sobre políticas públicas. Em primeiro lugar os achados da pesquisa autorizam salientar como o fluxo político marca presença importante no 
processo de formulação. De fato, a política parece constituir-se no fluxo mais relevante dos três, permeando e relacionando-se com os demais, antes, durante, e após a formação da janela política.

Em segundo lugar, há que se ressaltar a comprovação do viés pouco convencional de garbage can ou "lata de lixo", impresso no Modelo dos Múltiplos Fluxos. Esses modelos desconsideram qualquer linearidade causal e ordenada com relação à criação de soluções depois do surgimento dos problemas. No caso do Projeto Teias - Escola Manguinhos, de fato, o modelo de território integrado de atenção à saúde já existia como construção teórica bem antes de surgir a oportunidade de experimentá-lo a partir de um problema reconhecido pelas comunidades do Complexo de Manguinhos. Assim, como última reflexão, cabe direcionar um olhar crítico para o território de Manguinhos e perguntar se todos esses diferenciais, essas transformações e esses aprendizados têm realmente contribuído para a melhoria da vida dos cidadãos, habitantes que ali, configuram-se como extremamente dependentes do SUS e que, em última análise, são a razão de ser das políticas públicas. Espera-se que todas as ideias, argumentos, análises e resultados, aqui apresentados, possam contribuir para avançar na temática da formulação de políticas públicas destinadas a comunidades de bairros populares não somente a de Manguinhos o que o debate contribua para subsidiar a construção de novas abordagens no processo de formulação de políticas públicas a partir do aporte teórico-metodológico que nos possibilitou o Modelo de Múltiplos Fluxos.

\section{REFERÊNCIAS}

ALMEIDA FILHO, N. O que é saúde? Rio de Janeiro: Fiocruz, 2011.

ANDRADE, L. O. M.; BEZERRA, R. C. R.; BARRETO, I. C. H. C. O Programa de Saúde da Família como estratégia de atenção básica à saúde nos municípios brasileiros. Revista de Administração Pública, v. 39, n. 2, p. 328-348, 2005.

BARDIN, L. Análise de conteúdo. Lisboa: Edições 70, 1977.

BAUMGARTNER, F. R.; JONES, B. Agendas and instability in American politics. Chicago: University of Chicago Press, 2010.

BOBBIO, N.; MATEUCCI, N.; PASQUINO, G. Dicionário de polític $a$. Brasília: Editora da UnB, 2002. 
CAPELLA, A. C. Perspectivas teóricas sobre o processo de formulação de políticas públicas. In: HOCHMAN, G.; ARRETCHE, M.; MARQUES, E. (Orgs). Políticas públicas no Brasil. Rio de Janeiro: Fiocruz, 2007. p. 87-122.

DYE, T. R. Mapeamento dos modelos de análise de políticas públicas. In: HEIDEMANN, F. G.; SALM, J. F. (Orgs). Políticas públicas e desenvolvimento. Brasília: UNB, 2009. p. 99132.

EASTERBY-SMITH, M.; THORPE, R.; LOWE, A. Pesquisa gerencial em administração: Um guia para monografias, dissertações, pesquisas internas e trabalhos de consultoria. São Paulo: Pioneira, 1999.

FERnANDES, T. M.; COSTA, R. G. R. História de pessoas e lugares: Memórias das comunidades de Manguinhos. Rio de Janeiro: Fiocruz, 2009.

FIOCRUZ. FioCruz. Rio de Janeiro: Fiocruz, 2008.

FREY, K. Políticas públicas: Um debate conceitual e reflexões referentes à prática da análise de políticas públicas no Brasil. Planejamento e Políticas Públicas, n. 21, p. 212-259, 2000.

GERSCHMAN, S. Políticas Públicas articuladas e intersetoriais: A política de saúde em questão. In: OLIVEIRA, F. B. (Org). Política de gestão pública integrada. Rio de Janeiro: FGV, 2008 p. 47-55.

GIL, A. C. Métodos e técnicas de pesquisa social. São Paulo: Atlas, 1989.

HEIDEMANN F. G. Do sonho do progresso às políticas de desenvolvimento. In: HEIDEMANN, F. G.; SALM, J. F. (Orgs). Políticas públicas e desenvolvimento. Brasília: UNB, 2009. p. 23-40.

HOPE, R.; VAN DE GRAAF, H.; VAN DIJK, A. Implementation research and policy design: problem tractability, policy theory and feasibility testing. International Review of Administrative Sciences, n. 53, p. 581-604, 1987.

HOWLETT, M.; RAMESH, M.; PERL, A. Política pública: seus ciclos e subsistemas. Rio de Janeiro: Campus, 2013.

KINGDON, J. W. Agendas, alternatives, and public policies. Illinois: Pearson, 2011.

LASSWELL, H. D. A Estrutura e a função da comunicação na sociedade. In: COHN, G. (Org). Comunicação e indústria cultural. São Paulo: T. A. Queiroz, 1987, p. 105-116. NORONHA, J. C.; MACHADO, C. V.; LIMA, L. D. O Sistema Único de Saúde - SUS. In: GIOVANELlA, L.; ESCOREL, S.; LOBATO, L. V. C.; NORONHA, J. C.; CARVALHO, A. I. (Orgs). Políticas e sistema de saúde no Brasil. Rio de Janeiro: Fiocruz, 2009. p. 435472.

REAd | Porto Alegre - Vol. 24 - No 1 - Janeiro / Abril 2018 - p. 179-207 
PAIM, J. S. O que é o SUS? Rio de Janeiro: Fiocruz, 2012.

RADAELLI, C. The role of knowledge in the policy process. Journal of European Public Policy. v. 2, n. 2, p.159-183, 1995.

RIVERA, F. J. U.; ARTMANN, E. Planejamento e gestão em saúde: histórico e tendências com base numa visão comunicativa. Ciência \& Saúde Coletiva. v. 15, n. 5, p. 2265-2274, 2010.

SABATIER, P; JENKINS-SMITH, H. Theories of the policy process. Columbia: Westview Press, 1999.

SECCHI, L. Políticas públicas: conceitos, esquemas de análise, casos práticos. São Paulo: Cengage, 2010.

SOUZA, C. Estado da arte da pesquisa em políticas públicas. In: HOCHMAN, G.; ARRETCHE, M.; MARQUES, E. (Orgs). Políticas públicas no Brasil. Rio de Janeiro: Fiocruz, 2007. p. 65-86.

TEIAS - PROJETO TEIAS ESCOLA MANGUINHOS. Disponível em (http://www.ensp.fiocruz.br/teias/), Acesso em 21 de maio de 2013.

VERGARA, S. C. Métodos de pesquisa em administração. São Paulo: Atlas, 2012.

VIANA A. L. Abordagens metodológicas em políticas públicas. Revista de Administração Pública, Rio de Janeiro v. 30, n. 2, p. 5-43, 1996.

VIEIRA, M. M. F. Por uma boa pesquisa (qualitativa) em administração. In: VIEIRA, M. M. F.; ZOUAIN, D.M. Pesquisa qualitativa em administração. Rio de Janeiro: FGV, 2004. p. $13-26$ 